\title{
PERSONAL SUBJECTIVITY IMPACT REDUCTION IN CHOICE OF SOUR CHERRY VARIETIES FOR ORCHARD ESTABLISHMENT USING FUZZY SYSTEM
}

\author{
Marija Paunovic ${ }^{1}$, Olivera Milutinovic ${ }^{2}$, Goran Puzic ${ }^{3}$ \\ *Corresponding authorE-mail: majap@rcub.bg.ac.rs
}

\author{
A R T I C LE I N F O \\ Original Article \\ Received: 13 December2017 \\ Accepted: 07 June 2018 \\ doi:10.5937/ekoPolj1802545P \\ UDC 005.311:[65.012.12:634.233]
}

Keywords:

sour cherry, choice of varieties, multi-criteria modelling, fuzzy system

JEL: C02, C52, C63, Q14

\begin{abstract}
A B S T R A C T
This paper analyzes the problem of multi-criteria decisionmaking methods (MCDM) when selecting the optimal type of sour cherry for planting. Choice of varieties in agriculture is a very complex problem and is usually characterized by the interaction of a large number of factors, including often limited resources and uncertain information (price, time). In this context, mathematical models can represent valuable support for farmers when deciding on the choice of crops and plants for planting. An integrated MCDM method is presented, along with expert knowledge and Fuzzy Interference System (FIS) for sour cherry varieties choosing. The proposed approach assists decision makers in complex calculations and diminishes the impact of personal subjectivity and perception in order to define the overall evaluation. Data is incorporated in proposed fuzzy system and validated by a numerical example.
\end{abstract}

(C) 2018 EA. All rights reserved.

\section{Introduction}

The global market value, production and harvested area of sour cherries have rapidly increased over the last 15 years and continue to grow, signifying their growing importance in the food and horticultural industries (FaoStat, 2015). Serbia was on seventh place in world production, with an average production of 98271 metric tons (FaoStat, 2013). Commercial sour cherry production is very important for Serbia, because most of the fruits are exported (or as frozen, either as canned or as fruit concentrates). Agricultural planning and varieties choice can nowadays be considered as MCDM problems. Quantity is not the only problem in sour cherry production. Quality should also be

1 Marija Paunovic, PhD Candidate, Department of Fundamentals Sciences, Faculty of Technical Science, University of Novi Sad, e-mail: majap@rcub.bg.ac.rs, ORCID ID: 0000-0001-5216-0039

2 Olivera Milutinovic, Assistant professor, Faculty of Law, Megatrend University, Bulevar umetnosti 29, 11000 Belgrade, Serbia, Phone: +381 112092 135, e-mail: omilutinovic@ megatrend.edu.rs, 0000-0002-9677-9025.

3 Goran Puzic, Associate Professor, The Graduate School of Business Studies Vrsac, Megatrend University, e-mail: puzicgoran@gmail.com, ORCID ID: 0000-0002-5574-0327. 
preserved through pre and postharvest treatments. The parameters for assessing the quality of saplings are variable and depend on specific purposes (South et al., 1989). There are many criteria by which a choice of sour cherry varieties for planting can be made, such as: appearance, yield, price, firmness and crispness, resistance to weather conditions, resistance to disease, harvesting resistance and transport, etc.

Selection problem is a multi-objective problem in which different criteria should be taken into consideration. It is essential to compare cherries according to the criteria that contribute to the achievement of the objectives of the agricultural enterprise. Various mathematical techniques have been used by the researchers for this problem. The decision maker needs to deal with both qualitative and quantitative factors.

The classical MCDM methods cannot effectively address decision problems incorporating imprecise and linguistic information. Soft computing techniques are group of unique methodologies, often complement to each other, and provide flexible information processing capabilities in solving real-life problems. One such technique is the fuzzy approach which can be used to solve very complex real-world decisionmaking problems such as a crop and plant choosing.

In this paper, an integrated MCDM method along with expert knowledge and FIS for sour cherry choice is presented. Evaluation of the criteria is done by using fuzzy logic and Fuzzy Inference System (FIS). Approximate reasoning algorithm modeling the human experts reasoning process much more realistically than the conventional expert systems. Proposed approach relieves decision makers from the complex calculations and reduces the impact of personal subjectivity.

\section{Literature review}

Agricultural planning and choice problems were formulated as multi-objective models (Mainuddin et al., 1997; Sarker, Quaddus, 2002; Joubert et al., 2007). Optimization techniques are widely used in complex practical problem solving in many areas. Although optimization problems in agricultural systems such as crop and plant choice (Detlefsen, Jensen, 2004) do exist, such as country-wide crop planning (Sarker et al., 1997), irrigation planning (Raju, Kumar, 1999), vegetable production (Francisco, Ali, 2006), etc. More optimization problems dealing with management of agricultural resources can be found in paper by Weintraub and Romero, 2006.

Two different mathematical formulations for the analyzed crop choice problem are provided by Filippi, et al., 2017. The first one represents a natural integer programming formulation looking for the crop-mix that maximizes the farmer's expected profit measured as the difference between revenues obtained by selling the harvested products and the production costs. The second model uses the maximization of the Conditional Value-at-Risk (CVaR) as objective function and looks for the crop-mix that allows to maximize the average expected profit under a predefined quintile of worst realizations. 
AHP method takes a significant place during the selection of MCDM techniques. A research conducted by Milovanović, Stojanović, 2016, represents a choice of cherry varieties for planting by the application of the AHP methodology. Critics of the AHP method indicate that significance of elements presents only some sort of arithmetic accuracy that does not reflect real or objective evaluation. AHP does not take into account the uncertainty associated with perceptions of a decision-makers (Gajovic et al.,2017).

During the planning, due to ambiguous or uncertain information caused by the vagueness of decision makers' subjective preference or the uncertainty of objective information, soft computing techniques are gaining an increasing importance in reallife problem solving.

Zenga et al., proposed the fuzzy multi-objective linear programming (FMOLP) model for crop planning with triangular fuzzy numbers and transformed the FMOLP model and its corresponding fuzzy goal programming (FGP) problem to crisp ones which can be solved by the conventional programming methods.

Adeyemo and Otieno present four strategies of a novel evolutionary algorithm, multiobjective differential evolution algorithm (MDEA). The four strategies, namely, MDEA1, MDEA2, MDEA3 and MDEA4 are adapted to solve the multi-objective crop planning model with multiple constraints.

\section{Determining the Criteria}

Sour cherry (Prunus cerasus L.) is one of the most tolerant to biotic and abiotic stresses (Lezzoni et al., 1990). Those characteristics make sour cherry more adaptable to a wide range of continental climatic conditions. It is a profitable fruit and widely used in industry. Sour cherries are consumed dried, frozen or as juice (concentrates).

In addition to having nutritional properties, it has been proven to be extremely useful fruit since it contains and has antioxidant and antiinflammatory properties. Due to this fact, sour cherry can be considered "functional food". The distinctive purplish-red colour of sour cherry juice is due to its anthocyanin content. Sour cherries have a high level of vitamin A (20\% of the recommended daily intake in $100 \mathrm{~g})$ and vitamin $\mathrm{C}(22 \%$ of the recommended daily intake in $100 \mathrm{~g}$ ). It belongs to the group of high quality delicacy fruit. Great interest in this fruit, both scientific and other public, has been caused by the fact that sour cherries contain a significant level of anthocyanin (Wang et al., 1997). Anthocyanin from sour cherries have been shown to possess strong antioxidant and anti-inflammatory activity and inhibit the growth of human colon cancer cells.

Beside yield and sapling cost, experts also take many other criteria into consideration when choosing varieties of sour cherries for planting. Each market has its own preferences and opinions on what constitutes a high quality sour cherry.

In the literature, the authors point out many flower and fruit traits that are important for choosing in sour cherry breeding. They emphasize bloom date, ripening date, fruit dimension and weight, pit weight, fruit soluble solids concentration, fruit color, flesh 
color, stem length and thickness. Also, resistance to diseases and season of maturity are important criteria. Yield per tree, easy separation of seed from fruit flesh, fitness to the mechanical harvest are also significant criteria in sour cherry cultivars.

In the case of sour cherries intended for table consumption, it is desirable that the fruit size is large (6-8 g). In processing varieties it is important to have good quality of meat, which is reflected in high content of dry matter, consistent sugar and acid ratio and high content of anthocyanin (in varieties with colored juice). Also, the variety of sour cherry should have a relatively small pit, whose participation in the weight of the fruits is less (it is desirable to be below 7\%) and that the skin is more easily separated from the meat.

Skin colour (Serrano et al., 2005), total soluble solid and acidity ratio are the main quality parameters of sour cherries and both determine consumer acceptance (Crisosto et al., 2003). Sour cherries deteriorate rapidly as consequence of weight loss, color changes, softening, surface pitting and loss of acidity (Bernalte et al., 2003).

Firmness is considered extremely important by industry. Fruit firmness and crispness are often associated with freshness in fruit (Fillion, Kilcast, 2002). Further studies about firmness and crispness have been conducted and discussed (Harker et al., 2002; Evans et al., 2010). The aroma of sour cherries has been studied by Poll and Lewis, Schmid and Grosch.

Extension of the season of cherry harvest, as one of the goals of breeding, is significantly less due to the longer supply of fresh fruits on the market, and to a greater extent due to more efficient use of labor and mechanization for the performance of harvesting and processing. Sour cherry harvest is done whether by hand or mechanical harvesters. The cost of harvesting by hand amounts up to $55 \%$ of all production costs in sour cherry (Brzozowski, 2005). In order for the sour cherries to be suitable for mechanized harvesting, they need to possess the following characteristics: upright growth of the branches, uniform maturation of the fruit, easy separation of the fruit from the stem, absence of leakage of juice in the separation of the fruit from the stem and good transportability of the fruits (Mišić, 1989). The major loss in quality after harvest includes moisture loss, softening, decay etc., so combination of good handling practice and applications of appropriate postharvest technology.

One of the criteria for choosing varieties of cherries for planting is the resistance to disease. The most important cherry pathogen is Blumeriella jaapii fungus, which causes leafiness. Experts are permanently working to isolate clones of cherries, with later ripening and increased resistance to some diseases.

Based on the best knowledge of experts, the criteria for the choice of sour cherries in this paper are: the price of saplings, the fruit dimension, the resistance of fruit to picking and transport, the yield of a particular variety and the resistance to disease. For this purpose, the experts are considering three types of cherries that are suitable for the processing and production: sour cherry Oblacinska, Sumadinka and sour cherry Meteor. The selection of these specific criteria is for illustrative purposes of the proposed model and depends on the preferences and needs of the concrete decision-maker (company). 


\section{Fuzzy system}

In this paper authors use a modified fuzzy system based on the application of fuzzy logic and approximate reasoning algorithms as introduced by (Gajovic et al., 2017). Input variables are determined by the expert (the price of sapling - $\mathrm{C} 1$, the fruit dimension - $\mathrm{C} 2$, the resistance of fruit to picking and transport - C3, the yield of a particular variety- C4 and the resistance to disease-C5). Each element may be low, good, or high. The output value of the fuzzy system is the evaluation of each criteria of recommended varieties of sour cherry, which can be very low, low, good, high, or very high.

The theory of approximate reasoning is a framework for computational modeling of human reasoning. This process mimics the human expert's reasoning process much more realistically than the conventional expert systems (Nafarieh, Keller, 1991). Methodology using fuzzy sets for the representation of human concepts and words, via the idea of linguistic variables. The primitive elements of an AR are a collection of variables, $C_{j}$ for $j=1, \ldots, n$, and they are the objects of interest in the current context. It is information about the value of these variables, together with the relationships between the values of these variables that constitute the knowledge base. Associated with each variable $C_{j}$ is a set $X_{j}$, which represents its domain and which indicates the allowable values for the variable.

The term rule, which is the most commonly used type of knowledge representation, can be defined as an IF-THEN structure that relates given information or facts in the IF part to some action in the THEN part. The IF part, called the antecedent (premise or condition) and the THEN part called consequent (conclusion or action). Rules can represent relations, recommendations, directives, strategies and heuristics.

IF antecedent1 and antecedent 2 and ... THEN consequent1.

Fuzzy logic allows both the antecedent and consequent to be fuzzy propositions. These fuzzy propositions comprise statements involving linguistic variables, which will have shades of meaning or varying degrees of truth. An antecedent of any rule may be a simple clause or may be a combination of number of clauses connected via the fuzzy logical operators AND, OR, NOT AND and NOT OR.

\section{The results of the model}

For the purpose of this work and model testing, we used data set provided by (Milovanović, Stojanović, 2016). The authors presented expert assessments of sour cherry varieties choice in the company 'Džervin', which will be used in our fuzzy system. Figure 1 shows the FIS chart with 5 input functions of each criterion that have the same shape. Input variables are the price of sapling $(\mathrm{C} 1)$, the fruit dimension $(\mathrm{C} 2)$, the resistance of fruit to picking and transport (C3), the yield of a particular variety $(\mathrm{C} 4)$ and the resistance to disease (C5). 
Figure 1. Fuzzy Inference System

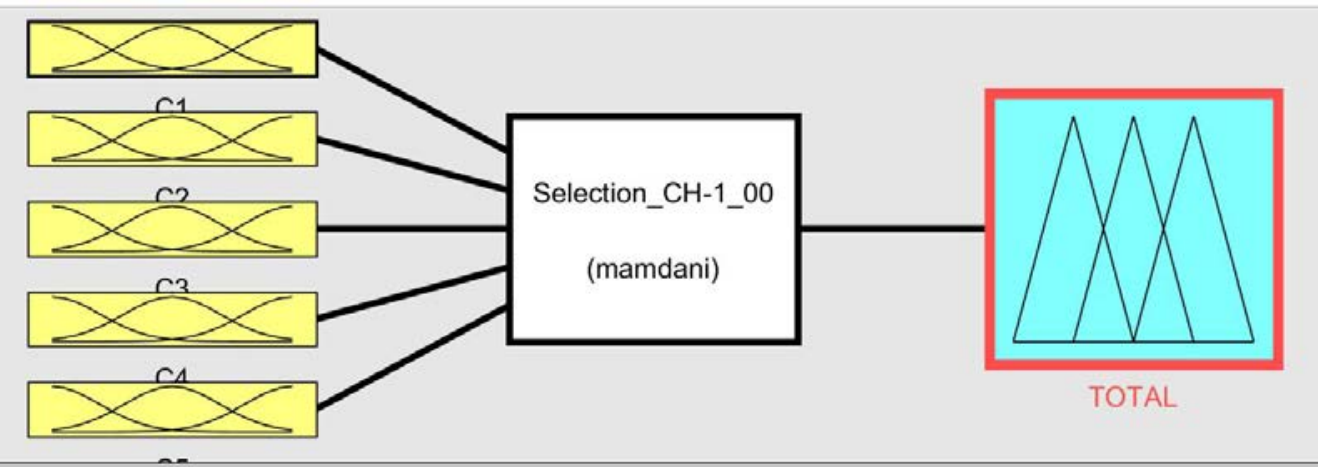

We built 243 rules and applied Mamdani inference technique (Figure 2). During the defuzzification process, we used centroid method.

Figure 2. Fuzzy rules

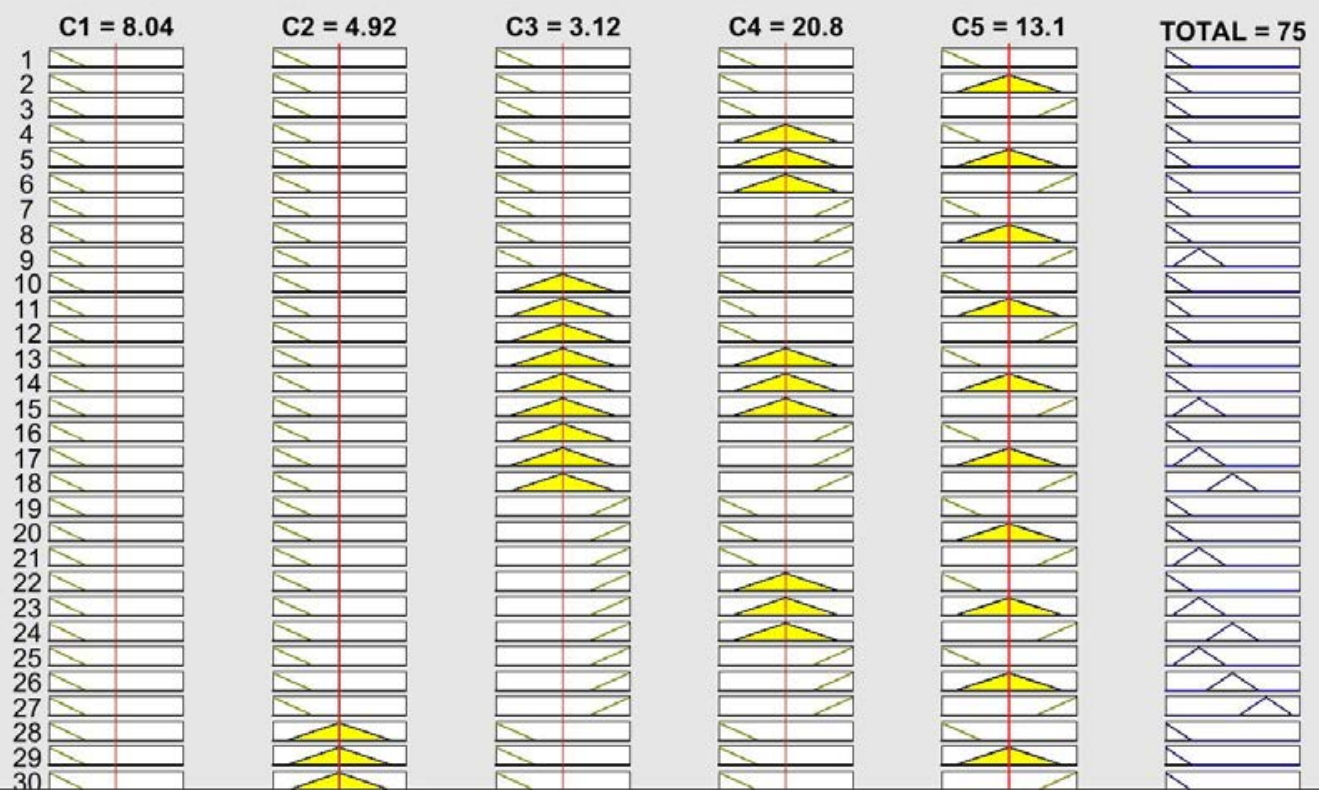

The output of the system is the total evaluation of given criteria, which can be very low, low, good, high or very high. The problem is solved using Matlab - Fuzzy logic designer. Simulation process is done with 1000 random values. Results of the system are shown in Table 1. 
Table 1. System output

\begin{tabular}{|l|c|c|c|c|c|}
\hline Variable & $\begin{array}{l}\text { Price of } \\
\text { sapling-C1 }\end{array}$ & $\begin{array}{l}\text { Dimension } \\
\text {-C2 }\end{array}$ & $\begin{array}{l}\text { Resistance (picking, } \\
\text { transport)-C3 }\end{array}$ & $\begin{array}{l}\text { Yield - } \\
\text { C4 }\end{array}$ & $\begin{array}{l}\text { Resistance to } \\
\text { disease-C5 }\end{array}$ \\
\hline AHP & 16,08 & 9,85 & 6,23 & 41,65 & 26,19 \\
\hline $\begin{array}{l}\text { Weighted } \\
\text { simulation values }\end{array}$ & 16,85 & 9,79 & 6,25 & 41,12 & 25,99 \\
\hline
\end{tabular}

The highest impact on the total evaluation of sour cherry choice has yield with $41.12 \%$ and resistance to disease of approximately $25.99 \%$. The sapling price for the observed company has an impact of $16.85 \%$. Fruit dimension and resistance to picking and transport have less impact on the total evaluation for the selected sour cherry variety $(9.85 \%$ and $6.23 \%$ respectively). In this way, all varieties of sour cherries can be evaluated in a very fast manner, in particular according to the given criteria, by partial analysis of various elements which affects the overall evaluation. This leads to a reduction of inadequate estimations in decision-making in the evaluation process. The proposed approach also allows direct implementation of expert knowledge in the fuzzy system, which frees users from complex calculations, but also reduces the possibility of error.

\section{Conclusion}

Fuzzy logic and its techniques are a valuable tool in real-life problem modeling. Expert evaluations are often subjective, under the influence of many criteria and sub-criteria, which may be related and interact between themselves. Integrated MCDM method along with expert knowledge and Fuzzy Inference System for sour cherry varieties choice is proposed. Based on the best knowledge of experts, the criteria for the choice of varieties of sour cherries in this paper are: the price of saplings, the fruit dimension and weight, the resistance of fruit to picking and transport, the yield of a particular variety and the resistance to disease. The obtained results indicate that the yield of sour cherries is the most important criterion in deciding on the choice of variety, followed by the resistance to disease.

Taking into account the variability, or uncertainty of the problem considered, the weight factors of the elements can easily be corrected in the fuzzy system. In this way, the model enables efficient implementation of newly-acquired information. Moreover, the fuzzy model provides a more precise numerical evaluation of the observed parameters.

\section{Conflict of interests}

The authors declare no conflict of interest. 


\section{References}

1. Adeyemo, J., \& Otieno, F. (2010). Differential evolution algorithm for solving multi-objective crop planning model. Agricultural Water Management, 97(6), 848-856. doi:10.1016/j.agwat.2010.01.013

2. Bernalte, M.J., Sabio, E., Hernandez, M.T., \& Gervasini, C. (2003). Influence of storage delay on quality of 'Van' sweet cherry. Postharvest Biol Tec, 28, 303-312

3. Brzozowski, P. (2005). Perspectives of sour cherry growing in Poland. XLIV Congress of fruit growers. Skierniewice, 27.10.2005, 68-75. [in Polish: Brzozowski, P. (2005). Skierniewice Perspektywy uprawy wiśni w Polsce. XLIV Zjazd Sadowników].

4. Crisosto, C.H., Crisosto, G.M., \& Metheney, P. (2003). Consumer acceptance of 'Brooks'and 'Bing' cherries is mainly dependent on fruit SSC and visual skin colour. Postharvest Biol. Technol. 28, 159-167.doi:10.10161/S09255214(02)00173-4.

5. Detlefsen, N.K., \& Jensen, A.L. (2004). A stochastic model for crop variety selection. Agric. Syst. 81(1), 55-72.

6. Evans, K., Brutcher, L., Konishi, B., Barritt, B. (2010): Correlation of sensory analysis with physical textural data from a computerized penetrometer in the Washing-ton State University apple breeding program, HortTechnology, 20(6), 1026-1029.

7. Food and Agriculture Organization of the United Nations (FAO). FAOSTAT Database. Available at: http://www.fao.org/statistics/en/

8. Filippi, C., Mansini, R., \& Stevanatoa, E. (2017). Mixed integer linear programming models for optimal crop selection. Computers and Operations Research, 81(C), 26-39. doi:10.1016/j.cor.2016.12.004

9. Fillion, L., \& Kilcast, D. (2002). Consumer perception of crispness and crunchiness infruits and vegetables. Food Qual. Prefer. 13, 23-29.

10. Francisco, S.R., \& Ali, M. (2006). Resource allocation tradeoffs in Manila's peri-urban vegetable production systems: an application of multiple objective programming, Agric. Syst. 87, 147-168.

11. Gajovic, V., Kerkez, M., \& Kocovic, J. (2018). Modeling and simulation of logistic processes: risk assessment with a fuzzy logic technique. Simulation. Transactions of the Society for Modeling and Simulation International, 94(6), 507-518. doi: 10.1177/0037549717738351

12. Harker, F.R., Maindonald, J., Murray, S.H., Gunson, F.A., Hallett, I.C., \& Walker, S.B. (2002). Sensory interpretation of instrumental measurements. 1: Texture of apple fruit. Postharvest Biol. Technol. 24(3), 225-239. doi:10.1016/ S0925-5214(01)00158-2

13. Joubert, J.W., Luhandjula, M.K., Ncube, O., le Roux, G., \& deWet, F. (2007). An optimization model for the management of a South African game ranch, Agric. Syst. 92, 223-239. 
14. Lezzoni, A., Schmidt, H, \& Albertain, A. (1990). Cherries (Prunus). In: Moore JN, Ballington JR (eds). Genetic resources of temperate fruit and nut crops. ISHS, Wageningen, pp. 109-174.

15. Mainuddin, M., Gupta, A.D., \& Onta, P.R. (1997). Optimal crop planning model for an existing groundwater irrigation project in Thailand. Agric. Water Manage. 33(1), 43-62. doi: 10.1016/S0378-3774(96)01278-4

16. Milovanović, Ž., \& Stojanović, M. (2016). Variety of cherries planting choice by the AHP methodology. Agroekonomika, 45(72), 11-19. [in Serbian: Milovanović, Ž., \& Stojanović, M. (2016). Izbor sorti višnje za sadnju primenom AHP metodologije].

17. Mišić, D.P. (1989). New varieties of fruits, Nolit, Belgrade. [in Serbian: Mišić, D.P. (1989). Nove sorte voćaka].

18. Nafarieh, A., \& Keller, J.M. (1991). A new approach to inference in approximate reasoning. Fuzzy Sets and Systems, 41(1), 18-36. doi:10.1016/01650114(91)90155-J

19. Poll, L., Petersen, M.B., \& Nielsen, G.S. (2003). Influence of harvest year and harvest time on soluble solids, titrateable acid, anthocyanin content and aroma components in sour cherry (Prunus cerasus L. cv. 'Stevnsbaer'), Eur. Food Res. Technol. 216, 212-216.

20. Raju, K.S., \& Kumar, D.N. (1999). Multicriterion decision making in irrigation planning. Agric. Syst. 62, 117-129.

21. Sarker, R., \& Quaddus, Q. (2002): Modelling a nationwide crop planning problem using a multiple criteria decision making tool. Computers Industrial Engineering, 42, 541-553.

22. Sarker, R., Talukder, S., \& Haque, A.F.M.A. (1997). Determination of optimum crop-mix for crop cultivation in Bangladesh. Appl. Math. Model. 21(10), 621632. doi: 10.1016/S0307-904X(97)00083-8.

23. Serrano, M., Guillen, F., Martìnez-Romero, D., Castillo S., \& Valero, D. (2005). Chemical constituents and antioxidant activity of sweet cherry at different ripening stages. J Agric Food Chem, 53:2741-2745.

24. South, D.B., Mexal J.G., \& Buijtenen van, J.P. (1989). The relationship between seedling diameter at planting and long term volume growth of loblolly pine seedlings in east Texas, South. Forest Nursery Management Cooperative, Auburn Univ. Auburn, Ala. Rep. No32. p. 8.

25. Schmid, W., \& Grosch, W. (1986). Quantitative-analysis of the volatile flavor compounds having high aroma values from sour (Prunus cerasus L.) and sweet (Prunus avium L.) cherry juices and jams, Z. Lebensm. Unters. Forsch. 183, 39-44.

26. Schwab, W., \& Schreier, P. (1990). Studies on bound aroma compounds of sour cherry fruit (Prunus cerasus L.), Z. Lebensm. Unters. Forsch, 190, 228-231. 
27. Wang, H., Nair, M.G., Strasburg, G.M., Chang, Y.C., Booren, A.M., Gray, J.I., \& DeWitt, D.L. (1999). Antioxidant and antiinflammatory activities of anthocyanins and their aglycon, cyanidin, from tart cherries, J Nat Prod. 62(2), 294-6.

28. Weintraub, A., \& Romero, C. (2006). Operations research models and the management of agricultural and forestry resources: a review and comparison. Interfaces, 36(5), 446-457.

29. Zenga, Xieting, Shaozhong Kanga, Fusheng Li , Lu Zhangc, \& Ping Guoa. (2010). Fuzzy multi-objective linear programming applying to crop area planning. Agricultural Water Management, 98 134-142. doi: 10.1016/j. agwat.2010.08.010 